\title{
Application of recycled tyre cord in concrete for shrinkage crack control
}

HWAI-CHUNG WU, YUN MOOK LIM, V. C. LI

Advanced Civil Engineering Materials Research Laboratory, Department of Civil and Environmental Engineering, University of Michigan, Ann Arbor, MI 48109, USA

Recently, there has been much attention focused on the rapidly deteriorating infrastructure. The main cause of the decay of infrastructure is the deterioration of the materials used in the construction and repair of the structures. In many types of infrastructure, such as highway and airport pavement, cracking behaviour is the most important factor for the determination of durability and lifetime of structures. For example, the control of the crack spacing and width is the main design criterion in continuously reinforced concrete pavement [1]. This type of cracking behaviour is related to environmental strain due to either dry shrinkage or thermal change in concrete structures with restrained boundary condition. Such shrinkage-induced cracking is very common in concrete, especially for large surfaceto-volume ratio structures such as highway pavement, slabs for parking garages, and walls [2]. Cracking can cause several problems in a reinforced concrete structure: durability problems related to the corrosion of rebars, spalling of structure surface, and increased permeability through the cracks, etc. Thus, the control of the shrinkage cracking behaviour in cementitious materials is considered an important factor for long-term structural performance.

In the past, research was conducted on the shrinkage behaviour of ordinary concrete and reinforced concrete structures. Recently, attention has focused on fibre reinforced cementitious composites [2-5]. It was found that the effect of discrete fibres is to reduce shrinkage cracking rather than reduce free shrinkage, although $10-25 \%$ reduction in free shrinkage in cementitious composites having steel fibre reinforcement has been reported $[6,7]$. Shrinkage cracking can, as expected, be significantly reduced by increasing the fibre volume fraction in cementitious composites [8].

In the above mentioned studies of shrinkage behaviour of fibre reinforced composites (FRCs), all composites were reinforced with various types of new virgin fibres including polypropylene and steel. Data on the shrinkage properties of concrete reinforced with recycled waste fibres are not available. Many industrial wastes can be recycled and utilized in building and highway construction. At present, most of these wastes are disposed of in landfills, which is of great environmental concern. For example, about 275 million used tyres are disposed of annually, and 3 billion used tyres have accumulated in waste piles across the United States [9]. No efforts have been made to reuse recycled tyre cord (such as nylon, polyester, and Kevlar), however, granulated rubber particles have been used in asphalt pavements with some success. Such recycled fibres can contribute to significantly improved composite properties when adequate fibre length and interfacial properties are achieved. This "properties-improvement" viewpoint (rather than mere consumption of wastes) can be efficiently fulfilled through guidelines obtained from a micromechanical model [10]. Recycled materials are expected to find a wide range of applications based on economic and performance advantages, at the same time solving disposal problems.

This letter reports on the free shrinkage and restrained shrinkage of a ring-type specimen of recycled tyre cord reinforced concrete. The effects of air plasma treatment of the tyre cord on the shrinkage behaviour of such composites are also examined. For comparison, virgin steel fibre (hooked ends, ZL 30/50, $30 \mathrm{~mm}$ long and $0.5 \mathrm{~mm}$ diameter), as commonly used in the construction industry, is included.

The tyre fabric ( $70 \%$ polyester, $15 \%$ nylon, $15 \%$ glass and some rubber residues) used in this study was retrieved by shredding disposed tyres. The fibres are of roughly $30 \mu \mathrm{m}$ diameter and 6 to $15 \mathrm{~mm}$ length. Some of the fibres are still in bundle form, as the tyre cord yarn. The fibre volume fractions of the recycled tyre fabric concrete are fixed at $2 \%$, whereas steel fibre is used at $1 \%$ volume fraction. In addition to the tyre fabric used "as-received", air gas plasma treatment of the fibres was also conducted, at a flow rate of $40 \mathrm{ml} / \mathrm{min}$ and power level of $150 \mathrm{~W}$ for $10 \mathrm{~min}$. Ordinary Type I cement with river sand and crushed aggregate (maximum size $9.6 \mathrm{~mm}$; cement:sand:aggregate $=1: 1.72: 1.72$ by weight) was used as the matrix of the composites. The water-to-cement ratio was 0.45 and the compressive strength of this concrete was $50.0 \mathrm{MPa}$. Superplasticizer ( $3 \%$ by solid weight) was used to improve workability.

The free drying shrinkage test followed the standard test method, ASTM C 596-89 and ASTM C 157. A ring test, similar to the ring-type specimens used in a restrained shrinkage study by Grzybowski and Shah [4], was adopted in this study. The dimensions of the specimen are shown in Fig. 1. Detailed information on specimen preparation and testing procedure can be found in [11].

The free shrinkage strain values at 48 days (including 3 days curing) of various composites are shown in Table I. The free shrinkage behaviour of concrete in this study agrees well with literature 


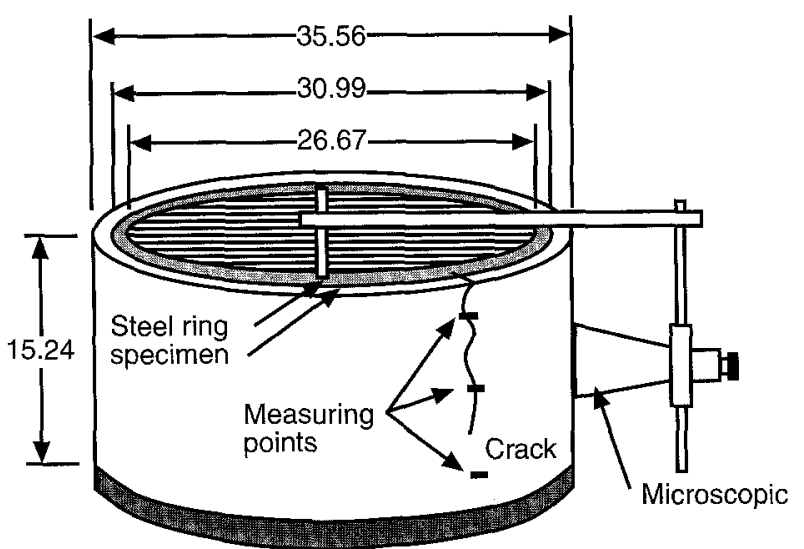

Plexiglass base

(unit: $\mathrm{cm}$ )

Figure 1 Specimen and measuring device for ring test.

data. The free shrinkage of steel fibre reinforced composite (SFRC) $\left(\mathrm{V}_{\mathrm{f}}=1 \%\right.$ ) is about $6 \%$ lower than that of concrete, and this result is similar to that of Malmberg and Skarendahl [6]. On the other hand, the free shrinkage of the recycled fibre composites is $34-55 \%$ higher than that of concrete. This adverse phenomenon might be attributed to the higher porosity in the composites compared to the plain concrete due to addition of the recycled fibres. The weight increase of a wet specimen (soaked in water for $30 \mathrm{~h}$ ) compared to a dry specimen (conditioned in an oven for $24 \mathrm{~h}$ at $110^{\circ} \mathrm{C}$ ) of recycled fibre composite specimens is higher than that of concrete or SFRC (see Table I).

Surface modification by plasma treatment decreases free shrinkage in the recycled tyre fabric composites (15\% reduction). Usually, surface modification by plasma treatment can improve the bond strength of virgin fibres [12]. However, the effect of plasma treatment on recycled fibres is not yet clear. Many different material residues are present in recycled fibres.

The restrained shrinkage cracking behaviour of various composites is illustrated in Fig. 2, and summarized in Table II. Fig. 2 illustrates the maximum crack width development with respect to

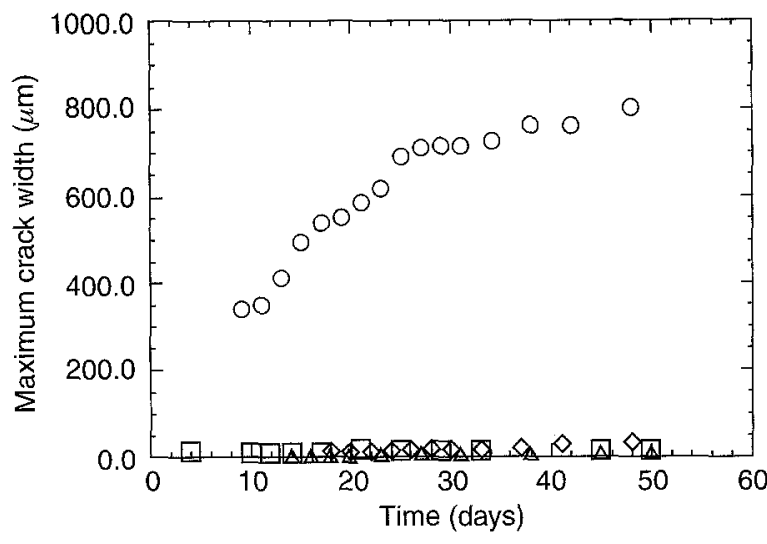

Figure 2 Maximum crack width in restrained shrinkage specimens: 0 concrete; $\triangle$ SFRC; $\square$ TFRC; $\triangle$ PTFRC.

time in each specimen. Table II reports the maximum crack width, total crack width, total number of cracks, number of through cracks and average crack spacing. Here, a through crack is a crack which goes through from the top to the bottom of the specimen. Except SFRC, the total crack width is equal to the maximum crack width since there is only one crack observed in each specimen.

As expected, crack widths are significantly reduced in the fibre composites (Table II and Fig. 3). In the tyre fabric reinforced composites (TFRC), crack width is comparable with crack width in SFRC, even though the free shrinkage is much higher than that of SFRC $(70 \%$ higher $)$. This reduction of crack width in TFRC and PTFRC can be explained by microscopic surface observations. In both cases, randomly distributed very fine cracks (less than $10 \mu \mathrm{m}$ ) are observed. There are almost no such cracks on the concrete and SFRC surface. PTFRC gives even smaller crack widths than TFRC. Again, this is consistent with the free shrinkage behaviour (which is $15 \%$ less in PTFRC than in TFRC).

The average flexural strength of the recycled fibre composites is given in Table III, together with toughness indices. There is no significant difference in flexural strength between the concrete and

TABLE I Free shrinkage of concrete and FRCs (age $=48$ days)

\begin{tabular}{lllcc}
\hline Material & Fibre type & $V_{\text {f }}(\%)$ & Shrinkage $\left(10^{-6}\right)$ & $\mathrm{W}^{*}(\%)$ \\
\hline Concrete & - & 0 & 808.3 & 6.82 \\
SFRC & Steel & 1 & 759.6 & 6.02 \\
TFRC & Tire fabric & 2 & 1253.3 & 7.23 \\
PTFRC & Tire fabric/P* & 2 & 1086.2 & 7.15 \\
\hline
\end{tabular}

$\mathrm{P}^{*}$ : Plasma treated, $\mathrm{W}^{*}$ : Weight increase when wet

TABLE II Restrained shrinkage test results (age $=48$ days)

\begin{tabular}{lcclll}
\hline Material & $\omega_{\max }(\mu \mathrm{m})$ & $\omega_{\mathrm{t}}(\mu \mathrm{m})$ & $N_{\mathrm{c}}$ & $N_{\mathrm{t}}$ & $S_{\text {avg. }}(\mathrm{cm})$ \\
\hline Concrete & 800.0 & 800.0 & 1 & 1 & - \\
SFRC & 35 & 41.7 & 2 & 0 & 55.86 \\
TFRC & 15 & 15 & 1 & 0 & - \\
PTFRC & 6.7 & 6.7 & 1 & 0 & - \\
\hline
\end{tabular}

$\omega_{\max }:$ maximum crack width, $\omega_{\mathrm{t}}$ : total crack width, $N_{\mathrm{c}}$ : number of cracks, $N_{\mathrm{t}}$ : number of through cracks, $S_{\text {avg. }}$ : average spacing of cracks 

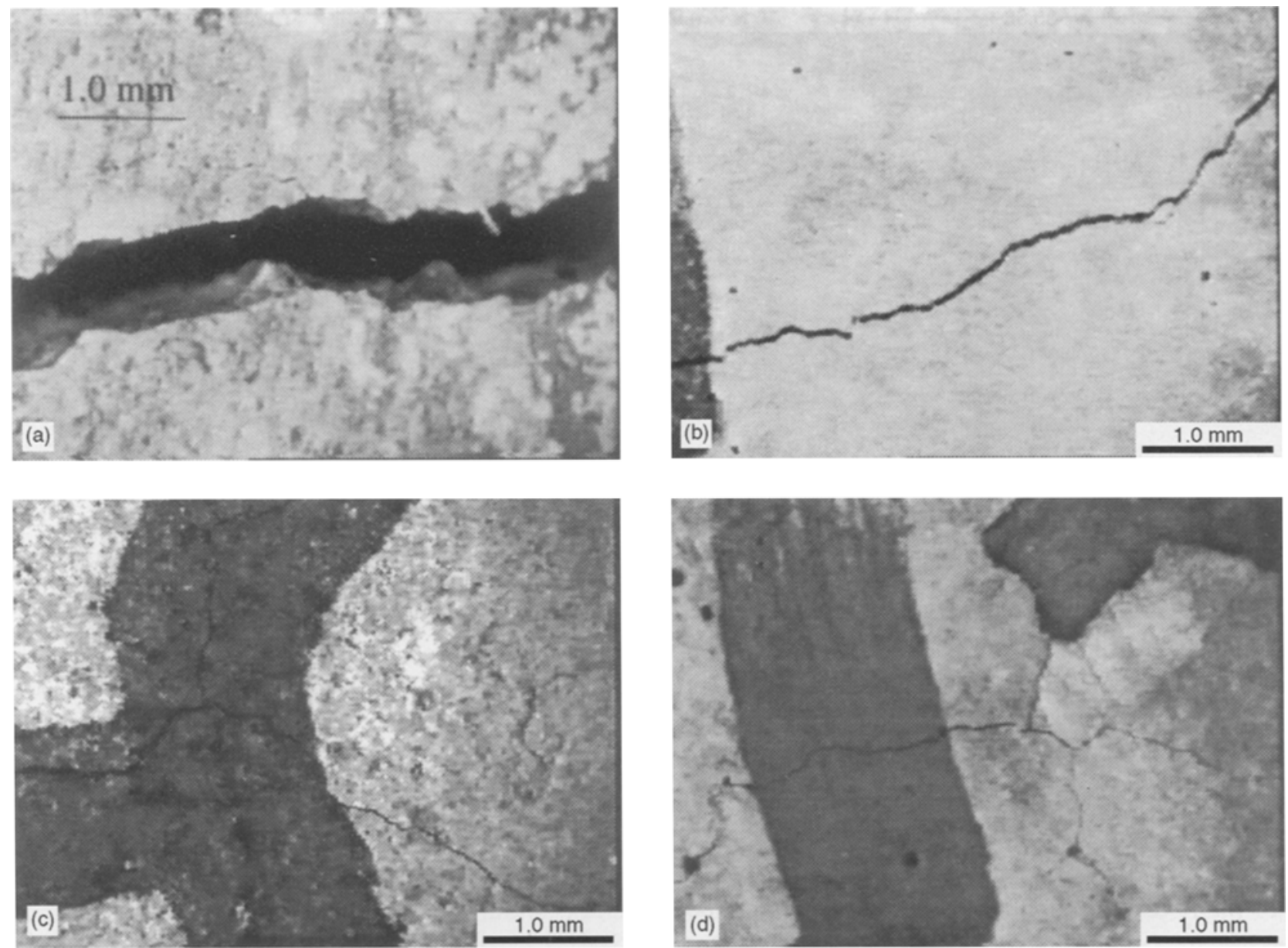

Figure 3 Computer scanned images of shrinkage crack width of various composites, same scale, dark ink is the reference mark on the specimen: (a) concrete; (b) SFRC; (c) TFRC; (d) PTFRC.

TABLE III Flexural strength and toughness indices (average of two tests)

\begin{tabular}{llll}
\hline Material & $\sigma_{\mathrm{f}}(\mathrm{MPa})$ & $I_{5}$ & $I_{10}$ \\
\hline Concrete & 4.40 & 1.00 & 1.00 \\
TFRC & 3.95 & 3.10 & 4.47 \\
\hline
\end{tabular}

recycled fibre composites. The major difference between the recycled fibre composites and concrete is in the toughness indices [13], an indication of toughness improvement as a result of the postcracking behaviour. Catastrophic ruptures were observed in the concrete, but some "ductility" was noticed in the recycled fibre composites (Fig. 4).

Cracking in concrete structures cannot be avoided because of the brittle nature of concrete materials. In practice, allowable crack width is limited to a given range, according to specific applications, by using steel reinforcement in order to improve durability of the reinforced concrete structures. The desirable crack width should be less than $0.1 \mathrm{~mm}$ for waterretaining structures and less than $0.4 \mathrm{~mm}$ for structures in dry air conditions [14]. Additionally, the allowable crack width in rigid pavement systems in $0.8 \mathrm{~mm}(0.03 \mathrm{in})$, permitting load transfer between crack surfaces by aggregate interlocking. The maximum crack widths in the concrete are close to the allowable crack width for pavements and are

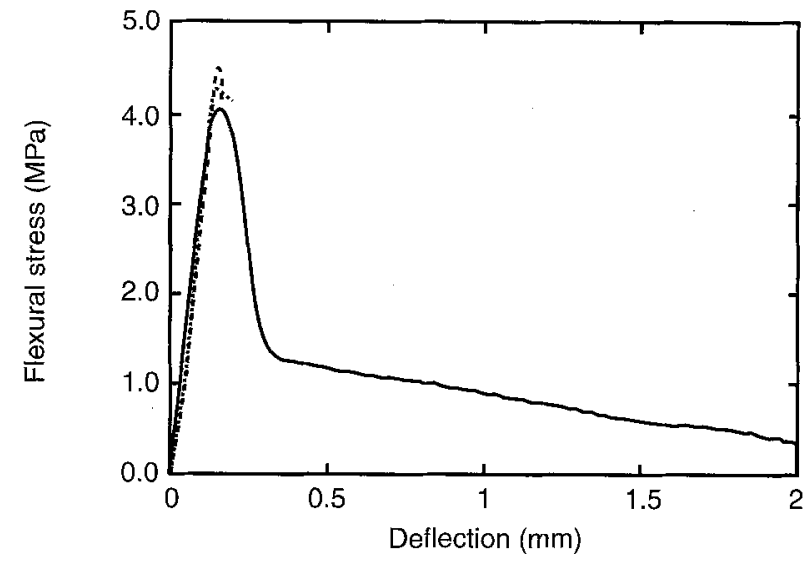

Figure 4 Typical flexural stress and deflection curves of composites: - - - concrete; - TFRC.

several times higher than the allowable crack width for reinforced concrete structures. It should be noted that the maximum crack width in this study cannot be directly compared with the allowable crack width of reinforced concrete structures since there is no steel reinforcement in our shrinkage specimens. On the other hand, our shrinkage specimens are only environmentally loaded, not mechanically loaded. The maximum crack width in the recycled fibre composites is two orders of magnitude smaller than the allowable crack width for pavement systems.

Water flow rate is highly sensitive to crack width 
under a constant fluid pressure [15]. In Tsukamoto's study, the flow rate was found to scale with the third power of crack width. For example, the maximum crack width of a recycled fibre composite is onetenth that of concrete; water flow rate of the concrete is about 1000 times larger than that of the composite. Even when this composite has more cracks, say five cracks, versus one crack in the concrete per unit area, the flow rate in the concrete is still 200 times larger if we assume flow rate increases linearly with the number of cracks. This aspect, obviously, requires further study. Water flow rate can be related to permeability of concrete structures. Permeability of a pavement is of particular importance for long-term performance, because permeated water through a crack can destroy the stability of subbase soil under a pavement. Dramatically reduced crack width, hence low permeability, can have a significant effect on the long-term behaviour of concrete structures including pavement systems.

The preliminary results of the present research suggest that the addition of recycled tyre fabric can improve the shrinkage performance of the recycled fibre reinforced concrete. Additional research should be conducted on tailoring the properties of fibre, matrix and interface so that the desired shrinkage behaviour of recycled fibre composites can be achieved with minimum fibre volume fractions. This performance-driven design approach has been found effective in structural applications [10]. Specifically, the influence of matrix additives (such as silica fume, fly ash and shrinkage reducing agent), fibre length and fibre surface modification on the shrinkage cracking property of recycled fibre composites should be studied.

In summary, the shrinkage behaviour of recycled tyre cord composites was investigated and compared with that of ordinary concrete and commonly used steel FRC. The free shrinkage of the recycled fibre composites was found to be $34-55 \%$ higher than that of concrete, whereas SFRC $\left(\mathrm{V}_{\mathrm{f}}=1 \%\right)$ was $6 \%$ lower than that of concrete. The maximum crack widths in restrained ring specimens of such composites were two orders of magnitude smaller than crack widths in concrete, similar to crack widths in SFRC, despite a $70 \%$ increase in free shrinkage. Fibre surface modification by air plasma treatment gave a $15 \%$ reduction of free shrinkage, and $55 \%$ reduction of maximum crack width in ring specimens of recycled tyre fabric composites. Finally, flexural strengths of recycled fibre composites was shown to be similar to that of concrete, with improved toughness. This behaviour is commonly observed for concrete reinforced with new virgin fibres.

\section{Acknowledgements}

The tyre fabric used in this study was supplied by Baker Rubber Inc. Part of this work has been supported by NSF grant MSS-9301949 to the University of Michigan.

\section{References}

1. B. F. McCULLOUGH, in "Concrete pavements", edited by Stock, A. F. (Elsevier Applied Science, New York, 1988) pp. 279-318.

2. S. P. SHAH, M. E. KARAGULER and M. SARIGAPHUTI, ACI Mater. J. 89 (1992) 289.

3. H. KRENCHEL and S. SHAH, in "Fibre reinforced concrete properties and application, SP 105 (American Concrete Institute, Detroit, 1987) pp. 141-158.

4. M. GRZYBOWSKI and S. P. SHAH, ACI Mater. J. 87 (1990) 138.

5. N. BANTHIA, M. AZZABI and M. PIGEON, Material and Structures 26 (1993) 405.

6. B. MALMBERG and A. SKARENDAHL, in "Testing and test methods of fibre cement composites, edited by R. N. Swamy, Proceedings of RILEM Symposium (The Construction Press, UK 1978) pp. 173-179.

7. P. N. BALAGURU and S. P. SHAH, "Fibre-reinforced cement composites" (McGraw-Hill, New York, 1992).

8. A. BENTUR and S. MINDESS, "Fibre reinforced cementitious composites" (Elsevier Applied Science, London, 1990).

9. NATIONAL RESEARCH COUNCIL, Strategic Highway Research Program, June, 1991.

10. V. C, LI, in Proceedings of 4th RILEM International Symposium on Fibre Reinforced Concrete, edited by R. N. Swamy (Chapmn and Hall, London, 1992) pp. 12-30.

11. H. C. WU, Y. M. LIM and V. C. LI, in "Waste materials and their geotechnical/geoenvironmental applications, edited by $R$. Salgado, Proceedings of 2 nd Annual Great lakes Conference, Purdue University, 1994, pp. 155-166.

12. V. C. LI, H. C. WU and Y. W. CHAN, in preparation, 1994.

13. Y. WANG, B. S. CHO and A. H. ZUREICK, in Proceedings of the Symposium on Recovery and Effective Reuse of Discarded Materials and By-Products for Construction of Highway Facilities, October 19-22, 1993 , Denver, Colorado.

14. ACI COMMitTeE 224, J. Amer. Concr. Inst. 69 (1972) 717.

15. T. TSUKAMOTO, Darmstadt Concrete 5 (1990) 215.

Received 13 June 1994

and accepted 10 October 1994 